Center for Research on Economic and Social Theory CREST Working Paper

Uniqueness of Cournot Equilibrium: New Results from Old Methods

Gerard Gaudet

Stephen Salant

August, 1988

$89-10$ 



\title{
Uniqueness of Cournot Equilibrium: \\ New Results from Old Methods
}

\author{
by \\ Gérard Gaudet \\ Département d'économique \\ Université Laval \\ Québec, Québec G1K 7P4 \\ and \\ Stephen W. Salant \\ Department of Economics \\ University of Michigan \\ Ann Arbor, Michigan 48109
}

Revised August 1988

We wish to thank Mark Bagnoli and especially Carl Simon for helpful comments on a previous draft of this paper. 
ABSTRACT

This paper provides a proof of a condition for uniqueness of Cournot equilibrium. Existing proofs of the same condition have shown it to imply a unique element within a limited class of Cournot equilibria, but leave open the possibility of other purestrategy equilibria outside this class. A simpler approach permits us to derive the condition and to rule out the possibility of these other equilibria. The approach used also provides new insight into the conditions for existence of Cournot equilibrium. 
Consider an industry composed of $\mathrm{N}$ firms producing a homogeneous good. Firm $i$ produces the good in quantity qi $\geq 0$. Its cost function is $C_{1}\left(q_{1}\right)$, defined for all qi 20 . The inverse demand function for the $\operatorname{good}$ is $p(Q)$, where $Q=\sum_{1=1}^{N} q_{1}$ is the total industry output.

Assume that:

A.1 There exists a $\xi \in(0, \infty)$ such that $\mathbf{p}(\mathbf{Q})>0$ for $Q \in[0, \xi)$ and $P(Q)=0$ for $Q \geq \xi$.

A.2 $p(Q)$ is twice continuously differentiable and $p^{\prime}(Q) \leq 0$ for $Q \in[0, \xi)$.

A.3 $C_{i}\left(q_{i}\right)$ is twice continuously differentiable and, for any $q_{i}>0, C_{i}\left(q_{1}\right)>C_{i}(0), i=1, \ldots, N$.

A.4 For all $Q \in[0, \xi)$ and $i=1, \ldots, N$, there exists some $\alpha<0$ (possibly dependent on $Q$ and i) such that $P^{\prime}(Q)-C_{i}^{\prime \prime}\left(q_{i}\right) \leq \alpha<0$.

For any cost function satisfying A.3 and A.4, define the extended function, $\Gamma_{i}\left(x_{i}\right)$, as follows:

$$
r_{i}\left(x_{i}\right)= \begin{cases}c_{i}\left(x_{i}\right) & \text { if } x_{i} \geq 0 \\ c_{1}(0)+c_{1}^{\prime}(0) x_{i}+\frac{1}{2} C_{i}^{\prime \prime}(0) x_{1}^{2} & \text { if } x_{i}<0\end{cases}
$$

Note that $\Gamma_{1}\left(x_{i}\right)$ is twice continuously differentiable for any $x_{i} \epsilon(-\infty, \infty)$. Moreover, since $\Gamma_{i}^{\prime \prime}\left(x_{1}\right)=C_{i}^{\prime \prime}(0)$ for $x_{i}<0$ and $A .4$ holds for qi 20 , then for all $Q \in[0, \xi)$ and $x_{1} \in(-\infty, \infty)$, $i=1, \ldots, N$, there exists some $\alpha<0$ (possibly dependent on $Q$ and $i)$ such that $p^{\prime}(Q)-\Gamma_{i}^{\prime \prime}\left(x_{i}\right) \leq \alpha$. Thus the appropriately modified A. 3 and A.4 must hold for the extended function.

$$
\text { Define } g_{i}\left(x_{1}, Z\right)=p(Z)+x_{i} p^{\prime}(Z)-\Gamma_{i}^{\prime}\left(x_{1}\right) \text {. Then Cournot }
$$
equilibria must satisfy: 


$$
g_{i}\left(q_{i}, Z\right) \leq 0, q_{i} \geq 0, g_{i}\left(q_{i}, z\right) q_{i}=0, \quad i=1, \ldots, N
$$

and

$$
\mathrm{Z}=\mathbf{Q}
$$

It is straightforward to verify that there exists at least one solution to (1) and (2). Consider first condition (1). By A.1 through A.3, the function $g_{i}\left(x_{i}, Z\right)$ has continuous partial derivatives for all $\mathrm{Z} \in[0, \xi)$ and $\mathrm{x}_{1} \in(-\infty, \infty)$. By A.4, its partial derivative with respect to $x_{i}$ is negative, bounded away from zero. There must therefore exist a unique $x_{1}(Z)$ such that $g_{i}\left(x_{i}(Z), Z\right)=0$. This implicit solution being unique, it must be continuous at all $\mathrm{Z} \in[0, \xi)$. For suppose it is discontinuous at some $Z^{0} \in[0, \xi)$. Then, in the neighborhood of $Z^{0}$, there exists no continuous solution to $g_{i}\left(x_{i}, Z\right)=0$ since $x_{1}\left(Z^{0}\right)$ is unique. But this violates the implicit function theorem at that point. It follows that condition (1) has a unique solution for all $Z \in[0, \xi)$, given by $q_{i}(Z)=\operatorname{MAx}\left[0, x_{i}(Z)\right]$. Now since $q_{i}(Z)$ is a continuous function of $Z$, so is $Q(Z)=\sum_{i=1}^{N} q_{i}(Z)$. We also know that $Q(0) \geq 0$, since $q_{i}(0) \geq 0$ for all $i=1, \ldots, N$. Furthermore, $Q(Z)=0$ for sufficiently large $Z$ since, by $A .1, p(Z)=0$ for $Z \geq \xi$ and hence, by $A .3, q_{i}(Z)=0$. There must therefore exist a $Z^{E}$ which solves $Q\left(Z^{B}\right)=Z^{E}$ and the corresponding $q_{1}^{R}\left(Z^{R}\right), i=1, \ldots, N$, constitutes a solution to (1) and (2).

We now provide a condition for the solution of (1) and (2) to be unique: 
Theorem: Assume that A.1 through A.4 hold. Then, if (only if) at al1 $q_{i}^{E}, i=1, \ldots, N$, we have:

$$
\sum_{i \in M\left(Q^{E}\right)} \frac{p^{\prime}\left(Q^{E}\right)+q_{i}^{E} p^{\prime \prime}\left(Q^{E}\right)}{C_{i}^{\prime \prime}\left(q_{i}^{E}\right)-p^{\prime}\left(Q^{E}\right)}<1(\leq 1)
$$

where $M\left(Q^{B}\right)=\left\{i \mid q_{i}\left(Q^{E}\right)>0\right\}$, there exists exactly one solution to (1) and (2).

Proof: Let $q_{i}^{\prime}(z)^{-}$and $q_{i}^{\prime}(z)^{+}$denote the left-hand and $r i g h t-h a n d$ derivatives of $q_{i}(z)$. The initial step of the proof is to establish that:

$$
\begin{aligned}
& q_{i}^{\prime}(z)^{+} \geq q_{i}^{\prime}(z)^{-} \\
& q_{i}^{\prime}(z)^{+}= \begin{cases}0 & \text { if } q_{i}(z)=0 \\
x_{i}^{\prime}(z) & \text { if } q_{i}(z)>0\end{cases}
\end{aligned}
$$

Since $x_{i}(Z)$ is unique for all $Z \in[0, \xi)$ and given A.4, we can again invoke the implicit function theorem to show that $x_{i}(Z)$ has a continuous derivative for $Z \in[0, \xi)$ and it is given by:

$$
x_{i}^{\prime}(Z)=\frac{p^{\prime}(Z)+x_{i}(z) p^{\prime \prime}(Z)}{C_{i}^{\prime \prime}\left(x_{i}(Z)\right)-p^{\prime}(Z)}
$$

If $x_{i}(Z)>0$ then $q_{i}(Z)=x_{i}(Z)>0$ and $q_{i}^{\prime}(Z)^{+}=q_{i}^{\prime}(Z)^{-}=x_{i}^{\prime}(Z)$. Thus (i) and (ii) both hold. If instead $x_{i}\left(Z^{\prime}\right)<0$ for some $Z^{\prime} \epsilon(0, \xi)$ then $q_{i}(Z)=0$ at $Z^{\prime}$ and in a neighborhood of $Z^{\prime}$, since $x_{i}(Z)$ is continuous at $Z^{\prime}$ and hence $x_{1}(Z)<0$ in some neighborhood of $Z^{\prime}$. Therefore $q_{i}^{\prime}\left(Z^{\prime}\right)^{+}=q_{i}^{\prime}\left(Z^{\prime}\right)^{-}=0$ and (i) and (ii) hold. Finally, if $x_{i}\left(Z^{\prime}\right)=0$ for some $Z^{\prime} \epsilon[0, \xi)$ then $q_{i}\left(Z^{\prime}\right)=x_{i}\left(Z^{\prime}\right)=0$. By continuity and nonnegativity of $q_{i}(Z), q_{i}^{\prime}\left(Z^{\prime}\right)^{-} \leq 0$ and $q_{i}^{\prime}\left(Z^{\prime}\right)^{+} \geq 0$. But A.2 and A.4 imply $x_{i}^{\prime}(z) \leq 0$ when $x_{i}(z)=0 ; \quad q_{i}^{\prime}\left(z^{\prime}\right)^{+}>0$ is therefore impossible. 
Hence $q_{i}^{\prime}\left(Z^{\prime}\right)^{-} \leq q_{i}^{\prime}\left(Z^{\prime}\right)^{+}=0$ and again (i) and (ii) hold.

Now let $Q^{\prime}(Z)^{+}$denote the right-hand derivative of $Q(Z)$. Then $Q^{\prime}(Z)^{+} \equiv \sum_{i=1}^{N} q_{i}^{\prime}(Z)^{+}=\sum_{i \in M_{M}(z)} q_{i}^{\prime}(Z)^{+}=\sum_{i \in E_{M}(z)} x_{i}^{\prime}(Z)$. The first inequality follows from the definition of $Q(Z)$, while the second and third follow from (ii). Moreover, (i) implies that $Q^{\prime}(Z)^{-} \leq Q^{\prime}(Z)^{+}$, and an upper bound on $Q^{\prime}(Z)^{+}$also bounds $Q^{\prime}(Z)^{-}$. It follows that if (only if) we have $Q^{\prime}\left(Z^{E}\right)^{+}<1(\leq 1)$, there must be only one $Z^{E}\left(=Q^{\mathbb{E}}\right)$ and hence only one $q_{i}^{\mathbb{E}}\left(Z^{\mathbb{B}}\right), i=1, \ldots, N$. But:

$$
Q^{\prime}\left(Z^{B}\right)^{+}=\sum_{i \in M\left(Z^{B}\right)} x_{i}^{\prime}\left(Z^{E}\right)=\sum_{i \in M\left(Z^{B}\right)} \frac{p^{\prime}\left(Z^{E}\right)+q_{1}\left(Z^{E}\right) p^{\prime \prime}\left(Z^{B}\right)}{C_{i}^{\prime \prime}\left(q_{i}\left(Z^{B}\right)\right)-p^{\prime}\left(Z^{E}\right)}
$$

and the condition stated in the theorem follows directly.1. Since any Cournot equilibrium must satisfy (1) and (2), A.1 through A.4 and (3) therefore insure that there exists at most, one cournot equilibrium. In addition, they identify the solution to (1) and (2) as the only candidate for the cournot equilibrium.2 Uniqueness follows if, for independent reasons, a cournot equilibrium is known to exist. This could be insured, for example, by further assuming that the profit function, $p\left(q_{i}+Y\right) q_{i}-C_{i}\left(q_{1}\right)$, is pseudoconcave in $q_{1}$ for $i=1, \ldots, N$ and any $Y \in\left[0, \xi-q_{1}^{\beta}\right)$. Conditions (1) and (2) then become both necessary and sufficient for cournot equilibrium.

Notice that if we require, in addition to A.1 through A.4, that a firm's marginal revenue be a non-increasing function of the output of its rivals, so that: 
$A .5 p^{\prime}(Q)+q_{i} p^{\prime \prime}(Q) \leq 0$ for $a 11 Q \in[0, \xi), q_{i} \leq Q, i=1, \ldots, N$ then condition ( 3 ) holds with strict inequality. Assumptions A.4 and A.5 combined also insure that each firm's profit function is strictly concave in its own output. Thus A.1 through A.5 insure existence of a unique Cournot equilibrium.

Assumption A.5 is frequently involved in discussions of existence of Cournot equilibrium (see in particular Novshek, 1985 and Shapiro, 1988). Given that $p^{\prime}(Q) \leq 0$ by A.2, it in fact is equivalent to the Novshek assumption that $\mathbf{p}^{\prime}(Q)+Q p^{\prime \prime}(Q) \leq 0$ for $Q \in[0, \xi)$. However, this assumption is unnecessarily strong for existence of equilibrium, given A.1 through A.4. For, any solution to (1) and (2) is a Cournot equilibrium if and only if $q_{1}^{E}$ yields a global maximum of $p\left(q_{i}+Q_{-i}^{E}\right) q_{i}-C_{i}\left(q_{i}\right)$, where $Q_{-i}^{E}=Q^{E}-q_{i}$ and $i=1, \ldots, N$. As long as this condition holds at some solution to (1) and (2), existence of a Cournot equilibrium is assured. It is unnecessary for existence of Cournot equilibrium to assume that this condition holds at every solution to (1) and (2). Moreover, at the designated solution to (1) and (2), it is unnecessary that $q_{i}^{B}$ be globally optimal in response to every aggregate output of the firms, but merely to $Q_{-i}^{\mathbb{E}}$. Finally, it is unnecessary that each firm's profit function be pseudoconcave, much less everywhere strictly concave.

The uniqueness condition (3) is the same as that derived by Kolstad and Mathiesen (1987) (equation (16), Corollary 3.1, p. 687) and by Kolstad (1988) (equation (5), Theorem 2, p. 4). The approach taken here is however much simpler and the proof much 
shorter than theirs. Moreover, their papers do not in fact establish conditions for uniqueness of Cournot equilibrium. They only establish conditions for the uniqueness of one class of Cournot equilibria, which they label "nondegenerate". In neither of those papers can the authors rule out the existence of one or more other Cournot equilibria where some of the $\mathbf{N}$ firms are just at the margin of becoming active or not, i.e., equilibria where $q_{i}=0$ and $g_{i}\left(q_{i}, Q\right)=0$ for some or all $i \notin M(Q)$ (see Definition 2 , p. 683 in Kolstad and Mathiesen, 1987, and pp. 2-3 in Kolstad, 1988). Hence, our results fill an important gap. Our approach is closest to that of Szidarovszky and Yakowitz (1977). They use it to show the existence of a unique Cournot equilibrium when marginal cost is increasing and inverse demand is downward sloping and concave. Their assumptions imply A.1 through A.5, but are, of course, unnecessarily strong. 
NOTES

1. Given A.1 through A.4 and (3), we will necessarily have $Z^{E} \in[0, \xi]$ and $Q(Z)-Z=0$ for all $Z \stackrel{<}{=} Z^{E}$, and the method p. 40) would in such a case rapidly converge to the unique solution to (1) and (2).

2. Not every solution to (1) and (2) need be a Cournot equilibrium. Although (1) and (2) insure that each firm selects a point in reply to the outputs of the other firms which satisfies the necessary conditions for a local maximum of its profit function, this need not be a local best reply, much less a global best reply, for every firm. 
REFERENCES

Conrad, Jon M. and Clark, Colin W. (1987), Natural Resources

Economics: Notes and Problems, Cambridge: Cambridge University Press.

Kolstad, Charles D. (1988), "A Constructive Proof of a Theorem on the Uniqueness of a Cournot Equilibrium", Faculty Working Paper No. 1444, Urbana-Champaign: University of Illinois, College of Commerce and Business Administration.

Kolstad, Charles D. and Mathiesen, Lars (1987), "Necessary and Sufficient Conditions for Uniqueness of a Cournot Equilibrium", The Review of Economic Studies, 54, 681-690.

Novshek, W. (1985), "On the Existence of Cournot Equilibrium." Review of Economic Studies, 52, 85-98.

Shapiro, Carl. (1988), "Theories of Oligopoly Behavior", in

Handbook of Industrial Organization, edited by Richard

Schmalensee and Robert D. Willig, New York: North Holland (forthcoming).

Szidarovszky, F. and Yakowitz, S. (1977), "A New Proof of the Existence and Uniqueness of the Cournot Equilibrium", International Economic Review, 18, 787-789. 


\section{Recent Crest Working Papers}

88 1: Carol A. Jones, Suzanne Scotchmer, "The Social Cost of Uniform Regulatory Standards in a Ilicrarchical Government" December, 1987.

88 2: 'Ted Bergstrom, Judy Roberts, Dan Rubinfeld, Perry Shapiro, "A Test, for Efficiency in the Supply of Public: Welucalion" December 12, 1987.

88 3: Mark Bagnoli, J. Bradley Barbeau, "Competition and Product Line Choice" February, 1988.

88-4: Severin Borenstein, Paul N. Courant, "How to Carve a Medical Degree: Human Capital Assets in Divorce Settlements" December, 1987.

88-5: Mark Bagnoli, Stephen W. Salant, Joseph E. Swierzbinski, "Pacman Refutes the Coase Conjecture: Durable-Goods Monopoly with Discrete Demand" January, 1988.

88-6: Jonathan Cave, Stephen W. Salant, “A Median Choice Theorem” December 29, 1987.

88-7: Mark Bagnoli, Naveen Khanna, "Why Are Buyers Represented by Seller's Agents When Buying a IIouse?" December, 1987.

88-8: Mark Bagnoli, Roger Gordon, Barton L. Lipman, "Takeover Bids, Defensive Stock Repurchases, and the Efficient Allocation of Corporate Control" October, 1987.

88 9: Mark Bagnoli, Barton L. Lipman, "Private Provision of Public Goods can be Eflicient," November, 1987.

88 10: Michelle J. White, "Urban Commuting Journeys are Not "Wasteful"" February, 1988.

88 11: $\Lambda$ very Katz, “A Note on Optimal Contract Damages When Litigation is Costly" February, 1988.

88 12: Ted Bergstrom, Jeffrey K. MacKie-Mason, "Notes on Pcak Load Pricing" February, 1988.

88-13: Jerry A. Hausman, Jeffrey K. MacKie-Mason, "Price Discrimination and Patent Policy" February, 1988.

89-01: Mark Bagnoli, Severin Borenstein, "Carrot and Yardstick Regulation: Enhancing Market Performance with Output Prizes" October, 1988.

89-02: 'Ted Bergstrom, Jeffrey K. MacKie-Mason, "Some Simple Analytics of Peak-Load Pricing" Octobcr, 1988.

89- 03: Ken Binmore, "Social Contract I: Harsanyi and Rawls" June, 1988.

89-04: Ken Binmore, "Social Contract II: Gauthier and Nash" June, 1988.

89-05: Ken Binmore, "Social Contract III: Evolution and Utilitarianism" June, 1988.

89 .06: Ken Binmore, Adam Brandenburger, "Common Knowledge and Game Theory" July, 1988.

89) 07: Jeffrey A. Miron, "A Cross Country Comparison of Seasonal Cycles and Business Cycles" Novemler, 1988 .

89-(08: Jeffrey A. Miron, "The Founding of the Fed and the Destabilization of the Post-1914 Econony" August, 1988.

89. 09: Gcrard Gaudet, Stephen W. Salant, "The Profitability of Exogenous Output Contractions: A Comparativc-

Static Analysis with Application to Strikes, Mergers and Export Subsidies" July, 1988.

89-10: Gerard Gaudet, Stephen W. Salant, "Uniqueness of Cournot Equilibrium: New Results from Old Methods" August, 1988.

89-11: Ilal R. Varian, "Gc sdness-of-Fit in Demand Analysis" September, 1988.

89-12: Michelle J. White, "Legal Complexity" October, 1988.

89 13: Michelle J. Whitc, "An Empirical Test of the Efficiency of Liability Rules in Accident Law" November, 1988.

89-14: Carl P. Simon, "Some Fine--Tuning for Dominant Diagonal Matrices" July, 1988. 



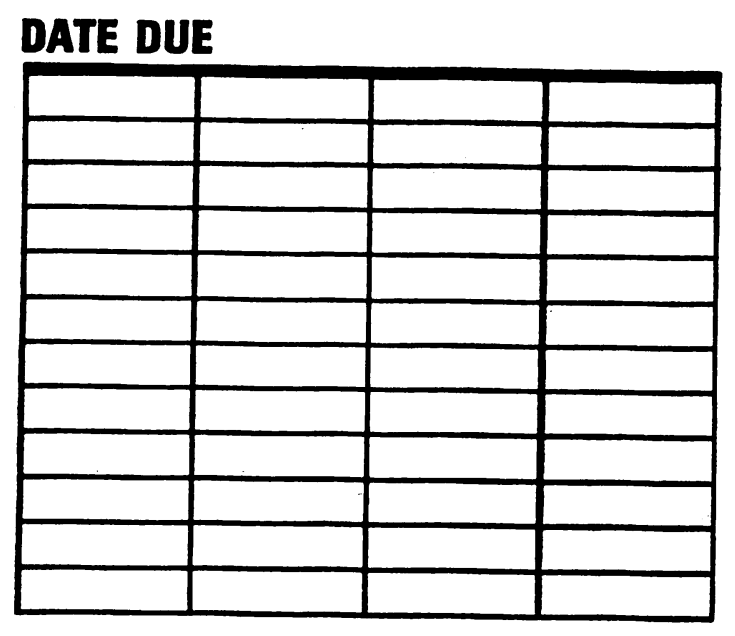


